\title{
Pengaruh Model Problem Based Learning Terhadap Hasil Belajar Siswa pada Materi Sistem Imun di SMA Negeri 6 Kendari
}

\author{
Hilda Ayu Melvi Amalia ${ }^{1}$; Siti Raoda ${ }^{2}$; Muh. Syarwa Sangila ${ }^{1}$; Hadi Machmud ${ }^{1}$; Samrin $^{1}$ \\ $\left.{ }^{1}\right)$ Dosen Fakultas Tarbiyah dan Ilmu Keguruan (FTIK), Institut Agama Islam Negeri (IAIN) Kendari; \\ 2) Alumni Prodi Tadris Biologi, FTIK, IAIN Kendari \\ Email Korespondensi: hildaayumelvi@gmail.com
}

\begin{abstract}
This article was aims to determine the effect of students' cognitive learning outcomes after being taught using the problem based learning model on the immune system material in SMA Negeri 6 Kendari. This type of research is quantitative research, with a quasi-experimental research method. Data analysis techniques were performed using descriptive analysis and inferential analysis. The samples in this study were class XI MIPA 5 (experimental class) and class XI MIPA 6 (control class), each with 20 students. The sampling technique is done by using purposive sampling technique. The results showed that there were significant differences between students' cognitive learning outcomes after being taught using the problem based learning model and after being taught using conventional models on the immune system material at SMA Negeri 6 Kendari, namely tcount 5.31 and ttable1.67 with a significance level of 5\%, so that tcount 5.31> ttable 1.67 then HO is rejected and Ha is accepted.
\end{abstract}

Keywords: Cognitive Learning Outcomes, Problem Based Learning Models, Conventional Models.

\begin{abstract}
ABSTRAK
Artikel ini bertujuan untuk mengetahui pengaruh hasil belajar kognitif siswa sesudah diajar dengan menggunakan model problem based learning pada materi sistem imun di SMA Negeri 6 Kendari. Jenis penelitian ini ialah penelitian kuantitatif, dengan metode penelitian quasi eksperimen. Teknik analisis data dilakukan dengan menggunakan analisis deskriptif dan analisis inferensial. Sampel pada penelitian ini yaitu kelas XI MIPA 5 (kelas eksperimen) dan kelas XI MIPA 6 (kelas kontrol), masing-masing sebanyak 20 siswa. Teknik pengambilan sampel dilakukan dengan menggunakan teknik purposive sampling. Hasil penelitian menunjukkan bahwa terdapat perbedaan yang signifikan antara hasil belajar kognitif siswa sesudah diajar menggunakan model problem based learning dan sesudah diajar menggunakan model konvensional pada materi sistem imun di SMA Negeri 6 Kendari, yaitu $t_{\text {hitung }} 5,31$ dan $t_{\text {tabel }} 1,67$ dengan taraf signifikansi 5\%, sehingga $t_{\text {hitung }}$ 5,31 > $\mathrm{t}_{\text {tabel }} 1,67$ maka $\mathrm{H}_{0}$ ditolakdan $\mathrm{H}_{\mathrm{a}}$ diterima.
\end{abstract}

Kata Kunci: Hasil Belajar Kognitif, Model Problem Based Learning, Model Konvensional.

\section{PENDAHULUAN}

Pendidikan merupakan upaya meningkatkan kualitas Sumber Daya Manusia (SDM). Pendidikan pada hakekatnya merupakan proses memanusiakan manusia itu sendiri (Putra irawan, 2017). Hal ini sejalan dengan pengertian pendidikan yang tertuang dalam Undang-Undang Republik Indonesia Nomor 20 tahun 2003 tentang Sistem Pendidikan Nasional pada Pasal 1 Ayat 1 yang berbunyi: Pendidikan adalah usaha sadar dan terencana untuk mewujudkan suasana belajar dan proses pembelajaran agar peserta didik secara aktif mengembangkan potensi dirinya untuk memiliki kekuatan spiritual keagamaan, pengendalian diri, kepribadian, kecerdasan, akhlak mulia, serta keterampilan yang diperlukan dirinya, masyarakat, bangsa, dan Negara.Salah satu aspek penting dalam kehidupan manusia adalah pendidikan. Persepsi tentang pentingnya pendidikan sejalan dengan ajaran agama Islam. Begitu banyak firman Allah Swt dalam Al-quran yang membahas tentang pendidikan, salah satunya dalam QS. Al-Mujadilah ayat 11yang artinya: Niscaya Allah akan meninggikan orang yang beriman diantaramu dan orang-orang yang diberi ilmu pengetahuan beberapa derajat.

Pendidikan di Indonesia tidak terlepas dari penerapan sebuah kurikulum. Kurikulum adalah seperangkat rencana dan pengaturan mengenai tujuan, isi dan bahan pelajaran serta cara yang di gunakan sebagai pedoman penyelenggara kegiatan pembelajaran untuk mencapai tujuan pendidikan tertentu (Rusman, 2009). Kurikulum 2013 yang berbasis karakter dan berbasis kompetensi, antara lain ingin mengubah pola pendidikan dari orientasi terhadap hasil dan materi ke pendidikan sebagai proses (Sudijono, 2013). Guru dalam pelaksanaan pembelajaran mempunyai tanggung jawab profesional untuk mewujudkan tujuan pendidikan nasional. Guru berperan sangat penting dalam kegiatan pembelajaran, karena guru bertanggung jawab terhadap tujuan-tujuan pembelajaran yang ingin dicapai secara optimal. Dalam kegiatan pembelajaran peran guru sebagai fasilitator hendaknya memfasilitasi siswa dalam kegiatan pembelajaran, sedangkan guru sebagai motivator dimaksudkan guru 
memotivator siswa agar implikasi pembelajaran mengarahkan pada pembelajaran efektif dan efisien. Kegiatan pembelajaran yang dilakukan guru seharusnya dapat memberikan rasa tenang dan nyaman pada siswa, Karena akan dapat memberikan daya ingat yang berkepanjangan pada siswa (Sunilawati,2013). Model pembelajaran yang beragam bisa menjadi salah satu peningkatan hasil belajar siswa itu sendiri, karena dengan model yang menarik siswa dengan semangat mengikuti pembelajaran. Ilmu pengetahuan yang disampaikan oleh guru akan diserap dengan baik oleh siswa apabila ilmu pengetahuan yang diterima oleh siswa dari gurunya bukan bersifat hafalan tetapi ilmu pengetahuan tersebut melalui sebuah proses pemahaman. Berdasarkan pengamatan awal di SMA Negeri 6 Kendari dalam pembelajaran Biologi bahwa sebagian guru masih kurang menggunakan model pembelajaran yang sesuai dengan dengan materi yang diajarkan, dan sebagian masih menggunakan model konvesional sehingga terkadang siswa masih kurang aktif dalam kelas dan kurang memperhatikan materi yang disampaikan dan mengakibatkan siswa kurang memahami materi yang di ajarkan oleh guru. Model pembelajaran yang di gunakan belum bervariasi, sehingga berdampak pada rendahnya hasil belajar siswa.Untuk mengatasi permasalahan tersebut, Pendidik juga perlu mengadakan variasi dalam mengajar, dalam hal ini pendidik diharapkan mampu menerapkan model pembelajaran yang dapat menumbuhkan semangat belajar peserta didik (Sagala, 2005). Salah satu alternatif model yang memungkinkan dikembangkannya keterampilan berfikir siswa (penalaran, komunikasi, dan koneksi) yaitu pembelajaran berbasis masalah (Rusman,2006).

Berdasarkan hasil wawancara dengan guru mata pelajaran Biologi menyatakan bahwa hasil belajar dalam pembelajaran Biologi masih rendah, rendahnya hasil belajar Biologi terlihat dari nilai rata-rata yang diperoleh siswa belum mencapai kriteria ketuntasan minimum (KKM) yaitu 75\% yang ditetapkan disekolah, hasil ulangan siswa masih rendah, dan masih banyak siswa yang remedial karena tidak serius dalam melakukan pembelajaran Biologi. Maka inilah yang menarik peneliti untuk melakukan penelitian di SMA Negeri 6 Kendari.

\section{METODE PENELITIAN}

Penelitian ini merupakan penelitian kuantitatif metode eksperimen. Penelitian yang digunakan untuk mencari pengaruh perlakuan tertentu terhadap yang lain dalam kondisi yang terkendalikan. Penelitian ini dilakukan di SMA Negeri 6 Kendari. Populasi penelitian ini adalah seluruh siswa kelas XI MIPA SMAN 6 Kendari yang berjumlah 6 kelas. Teknik pengambilan sampel dalam penelitian ini yaitu purposive sampling yaitu penggambilan sampel yang memiliki tujuan tertentu berdasarkan kebijakan guru. Alasan menggunakan purposive random sampling, yaitu Salah satunya agar kriteria atau syarat sampel yang dibutuhkan bisa benarbenar terpenuhi dan sesuai dengan kriteria dari sampel yang dibutuhkan dalam melakukan penelitian tersebut.Variabel pada penelitian ini terdiri atas variabel bebas yaitu model problem based dan variabel terikat yaitu hasil belajar kognitif siswa. Desain yang digunakan adalah posttest control design (Sugiyono, 2014) Instrumen penelitian dan teknik pengumpulan data dalam penelitian ini yaitu melalui tes, observasi dan dokumentasi. Teknik analisis data yang digunakan dalam penelitian ini yaitu analisis deskriptif dan analisis inferensial. Analisis deskriptif digunakan untuk menganalisis data dengan cara mendeskripsikan data yang telah terkumpul tanpa menarik kesimpulan atas populasi yang diamati. Teknik analisis deskriptif dilakukan dengan mencari nilai rata-rata (Nana Sudjana, 2006) dan standar deviasi (Muhammas Arif Tiro, 2007). Analisis inferensial digunakan untuk pengujian hipotesis penelitian. Uji hipotesis penelitian dilakukan dengan langkahlangkah: pengujian prasyarat analisis dengan uji normalitas menggunakan rumus lilifors( Sudjana, 2012)

\section{HASIL PENELITIAN}

Data hasil belajar siswa sesudah menggunakan model problem based learning dikelas eksperimen dan model konvensional dikelas kontrol, yang diperoleh dari hasil tes belajar Biologi siswa. Tes diberikan kepada siswa sesudah menggunakan model problem based learning dan siswa yang menggunakan model konvensional. Distribusi data hasil belajar siswa sesudah perlakuan disajikan pada tabel berikut:

Tabel 1. Rata-rata hasil belajar siswa sesudah menggunkaan model problem based learning pada kelas eksperimen dan model konvensional pada kelas kontrol

\begin{tabular}{|l|l|l|l|}
\hline No & Statistik & Kelas eksperimen & Kelas kontrol \\
\hline 1. & Nilai tertinggi & 95 & 85 \\
\hline 2. & Nilai terendah & 75 & 60 \\
\hline 3. & Rata -rata & 85,00 & 74,00 \\
\hline 4. & Standar deviasi & 6,283 & 6,806 \\
\hline
\end{tabular}

Pada tabel 1 diatas menunjukan bahwa hasil belajar siswa sesudah menggunakan model problem based learning memiliki nilai tertinggi, 95 nilai terendah ebesar 75, dan nilai rata-rata sebesar 85,00 lebih tinggi di bandingkan hasil belajarr siswa sesudah tanpa menggunakan model problem based learning memiliki nilai tertinggi sebesar 85, nilai terendah sebesar 60 , dan nilai rata-rata sebesar 74,00. 
Tabel 2. Distribusi frekuensi hasil belajar siswa sesudah menggunakan model problem based learning kelas eksperimen dan model konvensional kelas kontrol

\begin{tabular}{|l|l|l|l|l|l|l|}
\hline \multirow{2}{*}{ No } & \multicolumn{2}{l|}{ Kelas eksperimen } & \multicolumn{2}{l|}{ Kelas kontrol } \\
\cline { 2 - 8 } & Interval & Frekuensi & \% & Interval & Frekuensi & \% \\
\hline 1 & $75-79$ & 2 & 10 & $60-64$ & 1 & 5 \\
\hline 2 & $80-84$ & 6 & 30 & $65-69$ & 2 & 10 \\
\hline 3 & $85-89$ & 5 & 25 & $70-74$ & 6 & 30 \\
\hline 4 & $90-94$ & 4 & 20 & $75-79$ & 4 & 20 \\
\hline 5 & $95-99$ & 3 & 15 & $80-84$ & 5 & 25 \\
\hline & & & & $85-89$ & 2 & 10 \\
\hline
\end{tabular}

Dari tabel 2. jumlah siswa pada kelas eksperimen interval nilai 75-79 adalah 2 siswa atau 10\%. Jumlah siswa pada interval nilai 80-84 adalah 6 siswa atau 30\%. Jumlah siswa pada interval nilai 85-89 adalah 5 siswa atau 25\%. Jumlah siswa 90-94 adalah 4 siswa atau 20\%. Jumlah siswa pada interval nilai 95-99 adalah 3 siswa atau $15 \%$. Sedangkan dikelas kontrol jumlah siswa pada interval nilai 60-64 adalah 1 siswa atau 5\%, jumlah siswa pada interval nilai 65-69 adalah 2 siswa atau 10\%, jumlah siswa pada interval nilai 70-74 adalah 6 siswa atau 30\%, jumlah siswa pada interval nilai 75-79 adalah 4 siswa atau 20\%, jumlah interval nilai 80-84 adalah 5 siswa atau 25\%, jumlah siswa pada interval nilai 85-89 adalah 2 siswa atau 10\%. Secara jelas distribusi frekuens hasil belajar siswa sesudah menggunakan model problem based learning dan model konvensional disajikan dalam bentuk gambar berikut.

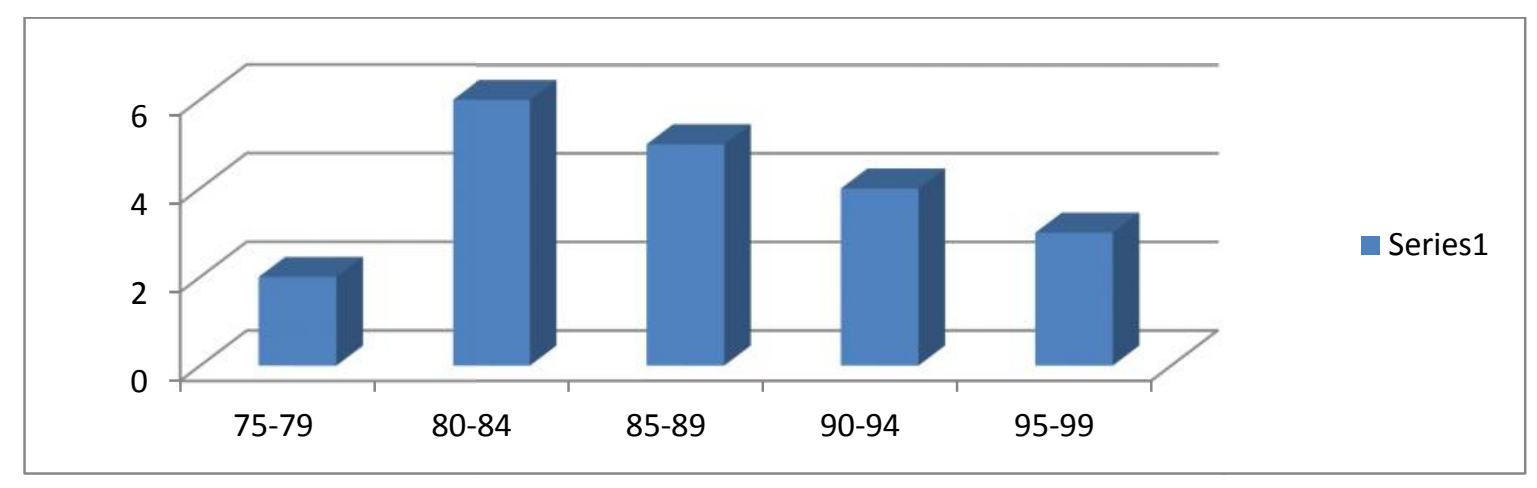

\section{Gambar 1. Distribusi frekuensi hasil belajar siswa kelas eksperimen}

Dari gambar histogram jumlah siswa pada interval nilai 75-79 adalah 2 siswa. Jumlah siswapada interval nilai 80-84 adalah 6 siswa. Jumlah siswa pada interval nilai 85-89 adalah 5 siswa. Jumlah siswa pada interval nilai 90-94 adalah 4 siswa. Jumlah siswa pada interval nilai 95-99 adalah 3 siswa.

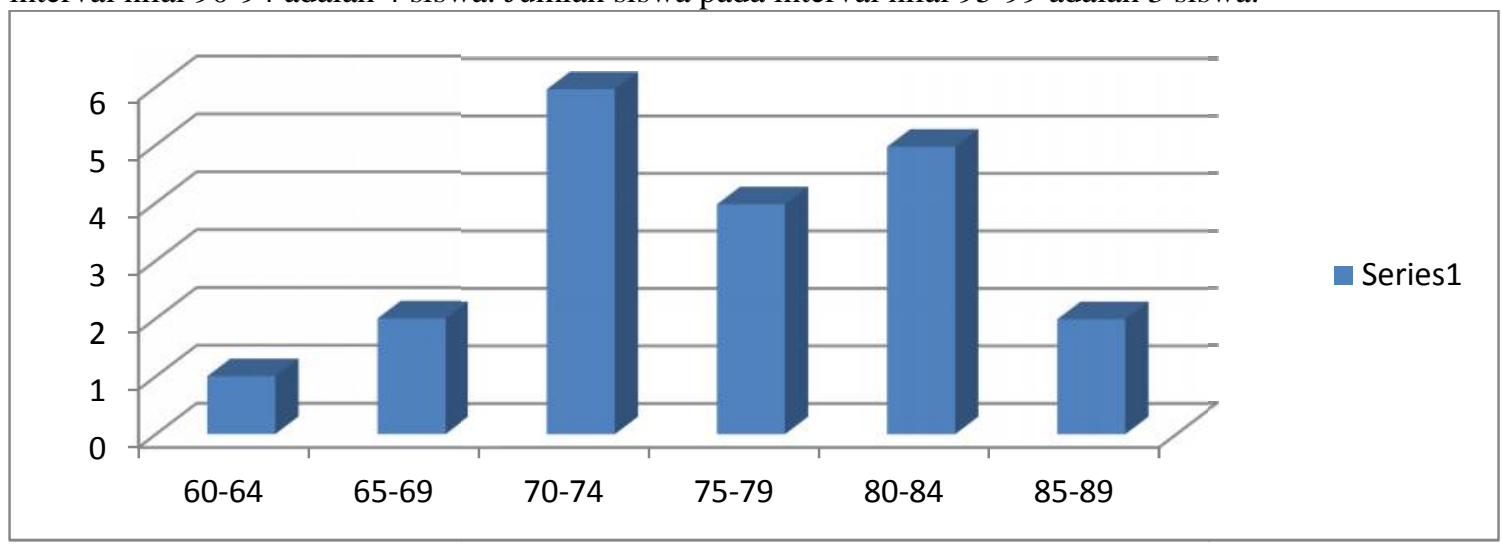

\section{Gambar 2. Distribusi frekuensi hasil belajar siswa kelas kontrol}

Dari gambar histogram jumlah siswa pada interval nilai 60-64 adalah 1 siswa, jumlah siswa pada interal 65-69 adalah 2 siswa, jumlah siswa pada interval nilai 70-74 adalah 6 siswa, jumlah siswa pada interval nilai 7579 adalah 4 siswa, jumlah siswa pada interval nilai 80-84 adalah 5 siswa dan jumlah siswa pada interval nilai 8589 adalah 2 siswa. 


\section{PEMBAHASAN}

Dalam proses pembelajaran pada penelitian ini dilakukan dua perlakuan yang berbeda yaitu menggunakan model problem based learning pada kelas eksperimen dan menggunakan model konvensionalpada kelas kontrol. Setelah pembelajaran berakhir, kelas eksperimen dan kelas kontrol diberi tes akhir (posttest) yang sama untuk mengetahui hasil belajar kognitif siswa dari perlakuan yang berbeda tersebut.Hasil analisis uji perbedaan hasil belajar kognitif siswa menunjukkan bahwa $t_{\text {hitung }} 5,311>\mathrm{t}_{\text {tabel }} 1,697$ artinya terdapat perbedaan yang signifikan hasil belajar siswa sesudah diajar dengan menggunakan model problem based learning dan sesudah diajar menggunakan model konvensional. Dari hasil tersebut, bahwa hasil belajar kognitif siswa menggunakan model problem based lebih tinggi daripada menggunakan model konvensional. Pada proses pembelajaran problem based learning siswa sangat antusias dan aktif dalam mengikuti pembelajaran dimana masing-masing siswa dituntut untuk mencari informasi mengenai permasaalahan yang telah diberikan. Dibandingkan dengan pembelajaran konvensional,sebagaiansiswa agak pasif dalam proses pembelajaran dimana yang lebih banyak terlibat adalah guru. Kegiatan pembelajaran problem based memiliki aktivitas yang di dalamnya membantu siswa untuk membiasakan diri belajar pada berbagai sumber dan meningkatkan ketertarikan siswa untuk lebih aktif sehingga memberikan pengalaman mengenai macam-macam permasaalahan yang ia hadapi dalam dunia nyata.Pada kelas XI MIPA 5 yang digunakan sebagai kelas eksperimen dari 34 siswa dan sampel yang diambil sebanyak 20 siswa. Dari 20 sampel yang diambil siswa yang memperoleh nilai tinggi dan sangat tinggi berdasarkan pengkategorian hasil belajar. Siswa yang memperoleh nilai sangat tinggi terdiri dari 11 orang dengan interval 85-100. Sedangkan siswa yang memproleh nilai tinggi terdiri dari 9 orang dengan interval 65-84. Dari interval 65-84 terdapat 2 siswa yang memperoleh nilai standar yakni 75. Pada kelas kontrol berdasarkan kategori nilai hasil belajar siswa tergolong dengan nilai yang dominasi tinggi berbeda dengan kelas ekperimen yang didominasi kategori tegolong sangat tinggi. Hal ini menjadi salah satu masalah yang terjadi selama pembelajaran dikarenakan dalam pembelajaran konvensinal guru yang lebih banyak berperan di banding siswa oleh karena itu sebagian siswa cenderung pasif, hal ini sesuai dengan pendapat Trianto yang mengatakan pada pembelajaran konvensional suasana kelas cenderung teacher-centered sehingga siswa menjadi pasif, siswa tidak diajarkan model belajar yang dapat memahami bagaimana belajar, berpikir dan memotivasi diri ( Triyanto, 2007) .Menurut Rizema Putra, Pembelajaran berbasih masalah adalah model pengajaran yang bercirikan adanya permasalahan nyata sebagai konteks untuk para peserta didik belajar berfikir kritis dan keterampilan memecahkan masalah serta memperoleh pengetahuan, hal ini sesuai dengan pendapat putra yang menyatakan bahwa problem based learning didefinisikan sebagai sebuah model pembelajaran yang didasarkan pada prinsip bahwa masalah bisa dijadikan sebagai titik awal untuk mendapatkan maupun mengintegrasikan ilmu baru (Putra, 2013).

Berdasarkan hasil belajar Biologi siswa kelas Problem Based Learning dan konvensional telah dibuktikan oleh beberapa peneliti sebelumnya yaitu dimana siswa yang diajarkan melalui model Problem Based Learning lebih baik dibandingkan dengan hasil belajar Biologi siswa yang diajarkan dengan menggunakan model konvensional. Antara lain: Ida, hasil penelitian menunjukkan bahwa hasil belajar Biologi siswa dengan model Problem Based Learning lebih tinggi dari pada hasil belajar biologi dengan model konvensional (Putra, 2012) . Model pembelajaran Problem Based Learning membuat siswa lebih memahami materi karena siswa menemukan pemecahan masalah permasalahan sendiri dengan bimbingan guru dan diskusi kelompok. Hal ini diperkuat oleh peneltian yang berjudul " Pengaruh Problem Based Learning berbasis Asesmen Kinerja terhadap hasil belajar IPA ditinjau dari gaya kognitif" yang meyatakan pengkondisian siswa belajar berkelompok yang saling berinteraksi dengan Guru dan temannya dapat meningkatkan pencapaian ketuntasan belajar dapat di harapkan. Sedanggkan pembelajaran konvensional lebih berpusat pada Guru.Adanya perbedaan yang signifikan hasil belajar kognitif siswa menggunakan model problem based learning dan model konvensionalmenunjukkan bahwa model problem based learning lebih unggul dari pada model konvensionaldalam meningkatkan hasil belajar kognitif siswa. Dalam proses pembelajaran problem based learning memberikan suasana yang aktif kompetisi selama proses pembelajaran dan siswa saling bertukar pikiran mengenai jawaban-jawaban dari permasaalahan yang yang telah diberkan. Dengan adanya permasaalahan yang diberikan melatih siswa untuk berfikir sssmengenai solusi dari permasaalahan yang ia dapatakan sehingga dapat meranggsang berpikir kritis siswa selain itu dapat menciptakan suasana kelas yang lebih hidup dan menyenangkan, sehingga antusiasme siswa dalam proses pembelajaran semakin bertambah, siswa juga dilibatkan secara langsung dalam pemecahan suatu masalah.

\section{KESIMPULAN}

Terdapat perbedaan yang signifikan hasil belajar kognitif siswa kelas XI MIPA 5 sesudah diajar menggunakan model problem based learning dan siswa kelas XI MIPA 6 sesudahdiajar menggunakan model konvensionalpada materi sistem imundi SMA Negeri 6 Kendari yang diperoleh dari hasil belajar siswa $t_{\text {hitung }}$ 5,311 dan $t_{\text {tabel }} 1,697$ dengan taraf signifikansi 5\%, sehingga $t_{\text {hitung }} 5,311>t_{\text {tabel }} 1,697$ maka $H_{0}$ ditolak dan $H_{a}$ diterima. 


\section{DAFTAR PUSTAKA}

Arikunto Suharismi. (2002) . (Prosedur Penelitian: suatu pendekatan praktek (Jakarta: Rineka cipta), h. 108

Irawan Putra, Susanna.(2017) .Tarmizi Hamid, "Perbedaan Hasil Belajar Melalui Model Problem Based Learning Dan Direct Instruction Siswa Kelas X Man Suak Timah Kabupaten Aceh Barat, Jurnal Ilmiah Mahasiswa Pendidikan Fisika, h. 114-121

Ida Bgs Nym Semara Putra. (2012) . "Implementasi Problem Based Learning (PBL) terhadap hasil belajar biologi SMA ditinjau dari intellegence Quotien (IQ)" tesis program studi pendidikan sains, program pascasarjana universitas pendidikan ganessha singaraja , h,8)

Made Ni Sunilawati, Nyoman Dantes, and I. Made Candiasa.(2013) "Pengaruh Model Pembelajaran Kooperatif Tipe STAD terhadap Hasil Belajar Matematika Ditinjau dari Kemampuan Numerik Siswa Kelas IV SD." PENDASI: Jurnal Pendidikan Dasar Indonesia 3.1.

Putra Rizema . (2013). Desain Belajar Mengajar Kreatif Berbasis Sains,( Jakarta:Diva Press,)

Sagala Syaiful. (2005). Konsep dan Makna Pembelajaran, (Bandung; Alfabeta), h.1

Sugiyono. (2014). Motode Penelitian Pendidikan (Cet Ke-16: Bandung: Alfabeta),h. 96

Sudijono Anas. (2013) Pengantar evaluasi pendidikan, (Jakarta : Rajawali Pers,), h. 40

Sudjana Nana. (2006). Penilaian Hasil Proses Belajar Mengajar. (Bandung: PT. Remaja Rosdakarya). h. 120.

Sudjana (2012). Metode Statistik, (Bandung: Tarsito), h. 456

(1996) Teknik Analisis Regresi dan Korelas Bagi peneliti,( Bandungg: Tarsito), h. 249

Rusman. (2016). Model-Model Pembelajaran: Mengembangkan Profesionalisme Guru Ed. 2 (Jakarta:Rajawali Pers, Cet-6), h.1

Tiro Muhammad Arif.( 2007). Dasar-dasar Statistik. (Makassar : Makassar State University Of Makassar), h. 133.

Triyanto.( 2007). Model-Model Pembelajaran Inovatif Berorientasi konstruktivistik. (Jakarta :Prestasi Pustaka), h, 1 